\begin{abstract}
Background: Chemokine-driven migration of inflammatory cells has been implicated in the pathogenesis of atherosclerotic conditions including peripheral arterial disease (PAD). Monocyte chemoattractant protein-1 (MCP-1) is elevated in patients with coronary artery disease and in hypertensive patients. This study therefore investigated MCP-1 in patients with PAD.

Methods: Serum MCP-1 was determined by enzymelinked immunosorbent assay in 36 healthy, control subjects and in 19 patients with PAD. Statistical analysis utilised the Mann-Whitney test and Spearman correlation $(p<0.05)$.

Results: MCP-1 (pg/ml) was increased in patients compared with in controls (mean \pm standard error of the mean: PAD group, $748 \pm 60$; control group, $459 \pm$ $27 ; p=0.0001)$. MCP-1 levels tended to decrease with progressing disease. From atherosclerosis risk factors, diabetes inclined to increase MCP-1 levels; hypertension had no effect. Serum MCP-1 correlated with cholesterol, triglycerides, low-density lipoprotein but not high-density lipoprotein.

Conclusion: Elevation of MCP-1 in the circulation of PAD patients shown in the present pilot study implicates this CC chemokine ligand 2 in inflammatory processes contributing to PAD clinical symptomatology. Further investigations are necessary to evaluate whether MCP-1 can be used as a potential marker of peripheral arterial disease follow-up and/ or prognosis.
\end{abstract}

Key words: Monocyte chemoattractant protein-1, CC chemokine ligand 2, Atherosclerosis, Artheritis obliterans, Risk factors, Low-density lipoprotein

\section{Monocyte chemoattractant protein-1 in patients with peripheral arterial disease}

\author{
Jana Petrkova ${ }^{1,2}$, Jaroslava Szotkowska', \\ Zuzana Hermanova ${ }^{1}$, Jan Lukl $^{2}$ and \\ Martin Petrek ${ }^{\text {CA1 }}$
}

${ }^{1}$ Department of Immunology and ${ }^{2}$ Department of Internal Medicine, Palacky University and Faculty Hospital, I. P. Pavlova str. 6, 77520 Olomouc, Czech Republic

\footnotetext{
${ }^{\mathrm{CA}}$ Corresponding author

Tel: + 420588442285

Fax: +420585415116

E-mail: petrekm@fnol.cz
}

\section{Introduction}

Chemokines (chemotactic cytokines) are low molecular weight polypeptides that, besides other functions, exert potent chemotactic and activating effects on specific leukocyte populations. ${ }^{1}$ Recently, there has been growing interest in applications of chemokine biology into clinic including cardiovascular disease, namely atherosclerosis. ${ }^{2}$ CC chemokine ligand 2, more widely known as monocyte chemoattractant protein-1 (MCP-1), is a potent mononuclear cell attractant. ${ }^{3}$ It has been previously implicated in the atherosclerosis development by mediating the influx of monocytes-macrophages into early atherosclerotic lesions. ${ }^{4}$ Recently, elevation of MCP-1 has been shown in patients with patients with coronary artery disease ${ }^{5}$ and in hypertensive patients. $^{6}$

Ischaemic heart disease is the most common form of atherosclerosis. There are, however, also other types of atherosclerosis such as thrombosis of other major vessels, ischaemic renal disease or peripheral arterial disease $(\mathrm{PAD}){ }^{7} \mathrm{PAD}$, also called artheritis obliterans, is characterised by generalised localisation of atherosclerotic lesions in the main arteries of the lower extremities, resulting in claudication symptomatology. ${ }^{8}$

To investigate whether MCP-1 is implicated also in the development of peripheral arterial disease, we have conducted the present pilot study, in which chemokine serum levels were determined by a sensitive immunoassay and comparisons made between control subjects and patients with PAD. MCP-1 levels were further compared between two patient subgroups with distinct disease course. The effect of known risk factors of atherosclerosis such as smoking, hypertension diabetes mellitus on MCP-1 serum levels was explored, as well as the relationship between the chemokine and lipid profile markers.

\section{Materials and methods}

\section{Study population}

MCP-1 protein levels were investigated in peripheral blood samples obtained from the cubital vein of 36 
control subjects (age [mean \pm standard deviation], 32.4 \pm 13.7 ; 27 males, nine females; 21 non-smokers, 15 smokers) and of 19 patients with PAD (age, 59.0 \pm 10.9 years; 18 males, one female; 13 non-smokers, six smokers). The diagnosis of PAD was based on characteristic clinical features together with typical results of angiography and non-invasive Doppler pressure assessment. ${ }^{8}$ The disease course was assessed according to Fontain (see, for example, Reference ${ }^{9}$ ), exploiting the claudication distance (cd): stage $2 \mathrm{a}, \quad \mathrm{cd}>400 \mathrm{~m} \quad(n=5)$; stage $2 \mathrm{~b}$, $\mathrm{cd}=200-400 \mathrm{~m} \quad(n=8) ;$ stage $2 \mathrm{c}, \quad$ cd $<200 \mathrm{~m}$ $(n=3)$; and stage 3 , ischaemic pain at rest $(n=3)$. The control group consisted of subjects without clinical signs of cardiovascular or any other inflammatory disease; absence of such disease in their medical history was also checked during the interview before blood collection. All patients and control subject in this study were from one referral centre, University Hospital Olomouc. The study was performed with the approval of the Ethics committee of this institution.

\section{Determination of MCP-1 protein}

MCP-1 protein levels in serum obtained from study participants were measured using a solid-phase sandwich enzyme-linked immunosorbent assay (Hbt kit; Hycult Biotechnology, Uden, the Netherlands). Briefly, $100 \mu \mathrm{l}$ of duplicated samples or standards (human MCP-1) were incubated (1 h, room temperature) in the wells pre-coated with primary anti-human MCP-1 antibody. After washing, biotinylated secondary anti-human MCP-1 antibody, and subsequently streptavidin-peroxidase conjugate, were added (both reagents for $1 \mathrm{~h}$ ). Finally, tetramethylbenzidine substrate solution was applied for $25 \mathrm{~min}$ and, after stopping the reactions by $2 \mathrm{M}$ sulfuric acid, the absorbance was measured at $450 \mathrm{~nm}$. The data were evaluated with KIM-E software; the detection limit of the MCP-1 assay was 6.0 $\mathrm{pg} / \mathrm{ml}$.

\section{Statistical analysis}

STAT100 (Biosoft, Ferguson, MO, USA) software was used to calculate basic statistical parameters and to perform the Mann-Whitney U-test to test for differences in chemokine protein levels between the PAD and control groups as well for further subanalysis. Spearman's rank correlation was used to assess the relationship between $\mathrm{MCP}-1$ and markers of lipid profile. $P<0.05$ was considered statistically significant.

\section{Results}

\section{MCP-1 in patients with PAD and in control subjects}

Detectable levels of MCP-1 were found in all investigated (patient and control) serum samples. Chemokine levels in the PAD group were elevated: in 16 of 19 patient samples (84\%), MCP-1 concentrations exceeded the median MCP-1 level of the control group (Fig. 1). The difference was highly significant $(p=0.0001)$.

When investigating a possible relationship between serum MCP-1 serum levels and disease course as defined by the degree of claudication symptoms, the patients with less severe symptomatology (stages $2 \mathrm{a}+2 \mathrm{~b}$; category I, $n=13$ ) and patients with advancing disease (stages $2 c+3$; category II, $n=6$ ) were grouped together. A trend towards a decrease of chemokine levels in patients with advancing disease (category II) was observed: category I (median \pm standard error of the mean $[\mathrm{SEM}]), 828 \pm 60 \mathrm{pg} / \mathrm{ml}$; category II, $693 \pm 105 \mathrm{pg} / \mathrm{ml}(p>0.05)$.

When we took into account the location of the atherosclerotic process in carotid arteries and divided patients accordingly, MCP levels were similar in patients with and without carotid artery involvement: without $(n=10), 721 \pm 77 \mathrm{pg} / \mathrm{ml}$; with $(n=9)$, $710 \pm 108 \mathrm{pg} / \mathrm{ml}$

\section{Effect of atherosclerosis risk factors on MCP-1 serum levels}

In order to explore effects of the known risk factors of atherosclerosis on serum MCP-1 levels in PAD patients, we first investigated patients with/ without concomitant diabetes mellitus. PAD patients with diabetes ( $\mathrm{D}+, n=4)$ tended to have higher MCP-1 levels than patients without diabetes (D-, $n=15$ ). However, due to the low number of subjects, the difference did not attain significance;

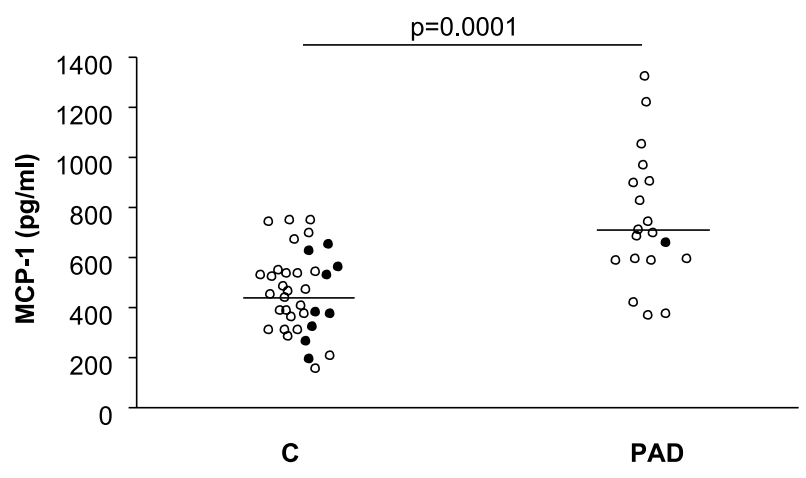

FIG. 1. MCP-1 serum levels $(\mathrm{pg} / \mathrm{ml})$ in healthy controls (C, $n=36)$ and in patients with PAD $(n=19)$. Open circles, individual MCP-1 values in male subjects; filled circles, chemokine values in female subjects; lines, median values. 
$\mathrm{D}+($ median \pm SEM $), 935 \pm 174 \mathrm{pg} / \mathrm{ml} ; \mathrm{D}-, 700 \pm 64$ $\mathrm{pg} / \mathrm{ml}(p>0.05)$.

By contrast, hypertension had no effect on MCP-1 serum levels: hypertensive patients, $>140 \mathrm{mmHg}$ (median \pm SEM), $726 \pm 58 \mathrm{pg} / \mathrm{ml}$; normotensive patients, $700 \pm 90 \mathrm{pg} / \mathrm{ml}$.

We also did not find a relationship between cigarette smoking and chemokine levels. Serum MCP-1 in smokers $(n=6)$ was not different from that of non-smokers $(n=13)$ (median \pm SEM [range]): smokers, $742 \pm 156 \mathrm{pg} / \mathrm{ml}(370-1320 \mathrm{pg} / \mathrm{ml})$; nonsmokers, $705 \pm 73 \mathrm{pg} / \mathrm{ml}(375-1220 \mathrm{pg} / \mathrm{ml})$.

There was no relationship between age and MCP-1 serum levels $\left(r_{\mathrm{s}}=0.04, p>0.05\right)$.

\section{Relationship between MCP-1 and markers of lipid profile}

To reveal whether MCP-1 levels in PAD patients are related to markers of lipid profile, correlations were tested between MCP-1 and serum levels of four markers in 18 patients (in one patient, complete data were not available). Significant association was observed between MCP-1 serum levels and serum cholesterol (Fig. 2A), serum low-density lipoprotein (LDL) (Fig. 2B), and also serum triglycerides. No association was found between MCP-1 and serum high-density lipoprotein $\left(r_{\mathrm{s}}=0.103, p>0.05\right)$.
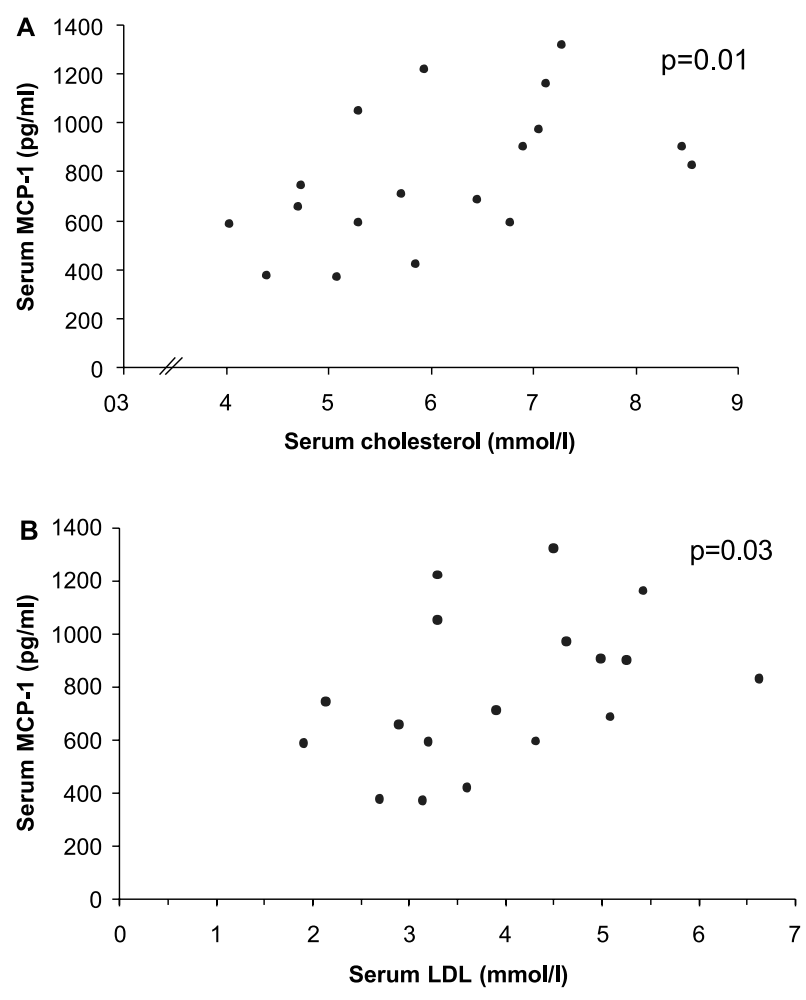

FIG. 2. Relationship between serum MCP-1 and serum cholesterol (A) or LDL (B). Circles, individual values of 18 patients. $p$ values are based on the values of the Spearman correlation coefficient.
Twelve patients have been receiving hypolipidaemic treatment $(\mathrm{T}+)$. However, this had virtually no effect on MCP-1 serum levels (compared with the subjects without treatment, (T-): $\mathrm{T}-, 721 \pm 129 \mathrm{pg} /$ $\mathrm{ml} ; \mathrm{T}+, 698 \pm 78 \mathrm{pg} / \mathrm{ml}$.

\section{Discussion}

Accumulation of mononuclear cells in the arterial intima of patients with atherosclerosis is believed to result from interplay between the trigger factors (e.g. oxidized LDL) and the cell adhesion molecules, chemokines and chemokine receptors. ${ }^{1}$ In the present study we have concentrated on a 'candidate' for monocyte attraction, the chemokine MCP-1 (CC chemokine ligand 2), in a specific form of atherosclerosis - PAD. We demonstrate here that this CC chemokine is elevated in circulation of patients with PAD. The data also indicate that MCP-1 is more elevated in serum of patients with earlier disease stages and may be associated with the presence of diabetes. Furthermore, chemokine levels detected in our PAD patients correlated with serum cholesterol, triglycerides and LDL but not with high-density lipoprotein.

MCP-1 expression has been extensively studied in cardiovascular disease but all studies have been performed either in patients with typical ischaemic heart disease or in hypertensive patients, ${ }^{10-13}$ and also in patients with myocarditis. ${ }^{14}$ However, except for a recent report by Matsui et al. ${ }^{15}$ there have been no further data on MCP-1 expression in PAD. Importantly, the results of small study by Matsui et $a 1 .{ }^{15}$ are in line with our findings: in their group of eight Japanese patients with peripheral arterial obstructive disease, an elevation of MCP-1 was observed. ${ }^{15}$ The relative paucity of published data on MCP-1 in PAD is, therefore, our main reason for reporting the results of our pilot study despite the number of enrolled patients not being high. It is indeed possible that many interesting differences in our patient subgroups will be presented differently if more patients are available, and therefore continuation of investigations of MCP-1 in PAD in our laboratory, and namely in other centres, is warranted.

Elevation of MCP-1 in PAD patients fits into the concept of promigratory and activating effects of this chemokine on monocytes - key cells of the early inflammatory process of the arterial wall. ${ }^{16}$ In this context, it is interesting to note that MCP-1 levels were highest in serum of the patients with less severe symptomatology (i.e. earlier disease stages) and they decreased with progressing disease. In our opinion, this finding should be explored further to provide rationale basis for possible inclusion of monitoring MCP-1 serum levels into the algorhythm of manage- 
ment of PAD patients. In this context, suggestion for possible clinical utilisation of MCP-1 as a surrogate marker of atherosclerotic inflammation is supported by finding that parenteral administration of prostaglandin $\mathrm{E}_{1}$ appeared to decrease circulating MCP-1 levels in eight patients with PAD. ${ }^{15}$ Suppression of the chemokine level by drugs, which is known to produce clinical benefit in PAD patients, is in line with the concept of MCP-1 involvement in the disease pathobiological mechanism.

In our PAD patients, MCP-1 levels were related to the markers of lipid metabolism (LDL, cholesterol, triglycerides). The same association has been reported in previous studies of patients with hypertensive disease. ${ }^{6}$ This confirms that the relationship between the chemokine and lipids is a general feature of atherosclerosis irrespective of its form and/or localisation. This finding is also in agreement with known in vitro observations that endothelial cells secrete MCP-1 in response to oxidation of LDL. ${ }^{17,18}$

One may argue that we are reporting already known associations between MCP-1 and coronary artery disease. This is, however, not the case. When chemokine protein levels observed in our PAD patients were compared with data recorded recently in our group of patients with coronary artery disease, MCP-1 protein was higher in PAD than in coronary atherosclerosis. This finding is in agreement with a report that PAD contributes to increase the inflammatory status in subjects with atherosclerosis. ${ }^{19}$

Also, an argument may arise that practical utilisation of MCP-1 measurements may be hampered due to a gender effect on MCP-1: there was an isolated report of increased MCP-1 levels in men compared with women. ${ }^{20}$ However, in our study there was predominance of men in both the control and the patient groups, and therefore a bias in our data and their interpretation is not probable. Furthermore, no gender effect on chemokine levels was apparent in our control group and the MCP-1 value detected in only one female was close to the median value of our patient group (Fig. 1). Despite the male sex generally being considered a risk factor for $\mathrm{PAD}^{8},{ }^{8}$ in a recent study of early-onset peripheral arterial occlusive disease more than one-half of patients were women. ${ }^{21}$ Importantly, the Rotterdam study, a population-based analysis of nearly 8000 patients, revealed that $17 \%$ of men and $21 \%$ of women aged 55 years and older had PAD. ${ }^{22}$ Future studies of the predictive value of the MCP-1 assay should therefore include equally men and women.

The present study, similar to other investigations of blood markers in PAD, ${ }^{19,23}$ exploited the standard method of drawing blood samples from the cubital vein irrespective of the location of claudication symptoms. Given the mechanism of the inflammatory cell recruitment by a gradient between systemic and local chemokine concentrations, ${ }^{1,24}$ it would be interesting to investigate whether differences occur between chemokine levels in blood samples taken from the contralateral arm and/or leg.

In conclusion, the findings of this pilot study extend previous observations of the MCP-1 role in inflammatory processes associated with atherosclerosis also to PAD. Further work is, however, necessary to define the MCP-1 relationship with the disease development more precisely and also to provide a definite answer to the question of whether measurements of this chemokine may be exploited for followup of patients with PAD.

ACKNOWLEDGEMENTS. Supported by a grant from the Czech Ministry of Health (IGA NI/7308-3). The technical assistance of Ms A. Vevodova and E. Kriegova is gratefully acknowledged. The authors thank Prof. R.M. du Bois for his helpful comments.

\section{References}

1. Mackay CR. Chemokines: immunology's high impact factors. Nat Immunol 2001; 2: 95-101.

2. Gerard C, Rollins BJ. Chemokines and disease. Nat Immunol 2001; 2 $108-115$

3. Vaddi K. Monocyte chemoattractant protein-1. In: Vaddi K, Keller M, Newton RC, eds. The Chemokine Fact Book, 1st edn, San Diego, CA: Academic Press, 1997: 86-98.

4. Valente AJ, Rozek MM, Sprague EA, Schwartz CJ. Mechanisms in intimal monocyte-macrophage recruitment. A special role for monocyte chemotactic protein-1. Circulation 1992; 86 (6 Suppl): III20-III25.

5. Matsumori A, Furukawa Y, Hashimoto T, et al. Plasma levels of the monocyte chemotactic and activating factor/monocyte chemoattractant protein-1 are elevated in patients with acute myocardial infarction. $J \mathrm{Mol}$ Cell Cardiol 1997; 29: 419-423.

6. Parissis JT, Venetsanou KF, Kalantzi MV, Mentzikof DG, Ziras NG, Karas SM. Macrophage chemoattractant protein and macrophage inflammatory protein-1alpha serum profiles in hypertensive patients with or without significant hyperlipidemia. Eur J Internal Med 2000; 11: 27-32.

7. Bierman EL. Atherosclerosis and other forms of arteriosclerosis. In: Wilson JD, Braunwald E, Isselbacher KJ, et al, eds. Harrison's Principles of Internal Medicine, 12th edn, New York: McGraw-Hill, 1991: 9921001

8. Ouriel K. Peripheral arterial disease. Lancet 2001; 358: 1257-1264.

9. Ramirez-Tortosa MC, Urbano G, Lopez-Jurado M, et al. Lifestyle changes in free-living patients with peripheral vascular disease (Fontaine stage II) related to plasma and LDL lipid composition: a 15 month follow-up study. Clin Nutr 1999; 18: 281-289.

10. Aukrust P, Ueland T, Muller F, et al. Elevated circulating levels of C-C chemokines in patients with congestive heart failure. Circulation 1998; 97: $1136-1143$.

11. Damas JK, Eiken HG, Oie E, et al. Myocardial expression of CC- and CXC-chemokines and their receptors in human end-stage heart failure. Cardiovasc Res 2000; 47: 778-787.

12. Gullestad L, Simonsen S, Ueland T, et al. Possible role of proinflammatory cytokines in heart allograft coronary artery disease. Am J Cardiol 1999; 84: 999-1003.

13. Aukrust P, Damas JK, Gullestad L, Froland SS. Chemokines in myocardial failure - pathogenic importance and potential therapeutic targets. Clin Exp Immunol 2001; 124: 343-345.

14. Fuse $\mathrm{K}$, Kodama $\mathrm{M}$, Hanawa $\mathrm{H}$, et al. Enhanced expression and production of monocyte chemoattractant protein-1 in myocarditis. Clin Exp Immunol 2001; 124: 346-352.

15. Matsui K, Ikeda U, Murakami Y, Yoshioka T, Shimada K. Intravenous prostaglandin E1 reduces monocyte chemoattractant protein-1 levels in peripheral arterial obstructive disease. Am Heart J 2003; 145: 330 - 333.

16. Davies MJ. The birth, growth, and consequences of the atherosclerotic plaque. Dialogues Cardiovasc Med 1999; 4: 115-130.

17. Maeno Y, Kashiwagi A, Nishio Y, Takahara N, Kikkawa R. IDL can stimulate atherogenic gene expression in cultured human vascular endothelial cells. Diabetes Res Clin Pract 2000; 48: 127-138.

18. Dwivedi A, Anggard EE, Carrier MJ. Oxidized LDL-mediated monocyte adhesion to endothelial cells does not involve NFkappaB. Biochem Biophys Res Commun 2001; 284: 239-244.

19. Brevetti G, Piscione F, Silvestro A, et al. Increased inflammatory status and higher prevalence of three-vessel coronary artery disease in patients 
with concomitant coronary and peripheral atherosclerosis. Thromb Haemost 2003; 89: 1058-1063.

20. Jilma-Stohlawetz P, Homoncik M, Drucker C, et al. Fy phenotype and gender determine plasma levels of monocyte chemotactic protein. Transfusion 2001; 41: 378-381.

21. Barretto S, Ballman KV, Rooke TW, Kullo IJ. Early-onset periphera arterial occlusive disease: clinical features and determinants of disease severity and location. Vasc Med 2003; 8: 95-100.

22. Meijer WT, Hoes AW, Rutgers D, Bots ML, Hofman A, Grobbee DE Peripheral arterial disease in the elderly: the Rotterdam Study. Arter ioscler Tromb Vasc Biol 1998; 18: 185-192.
23. McDermott MM, Green D, Greenland P, et al. Relation of levels of hemostatic factors and inflammatory markers to the ankle brachial index. Am J Cardiol 2003; 15: 194-199.

24. Call DR, Nemzek JA, Ebong SJ, et al. Ratio of local to systemic chemokine concentrations regulates neutrophil recruitment. $\mathrm{Am} J$ Pathol 2001; 158: $715-721$

\section{Received 25 October 2003}

Accepted 6 November 2003 


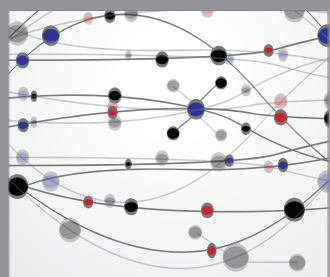

The Scientific World Journal
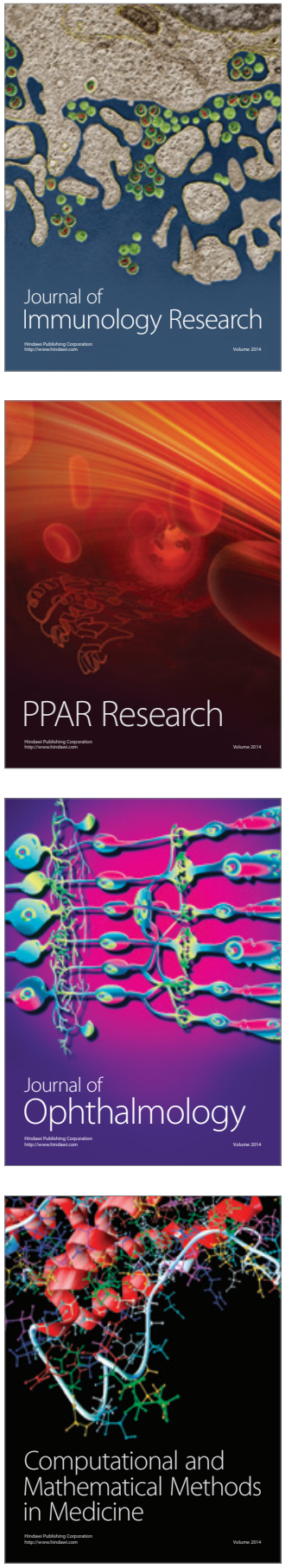

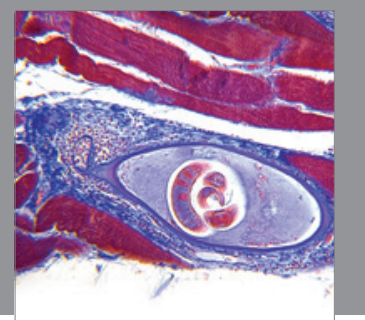

Gastroenterology

Research and Practice
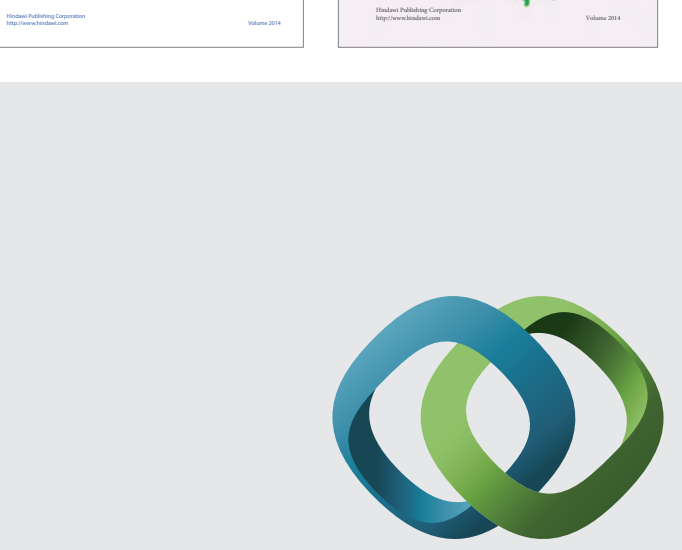

\section{Hindawi}

Submit your manuscripts at

http://www.hindawi.com
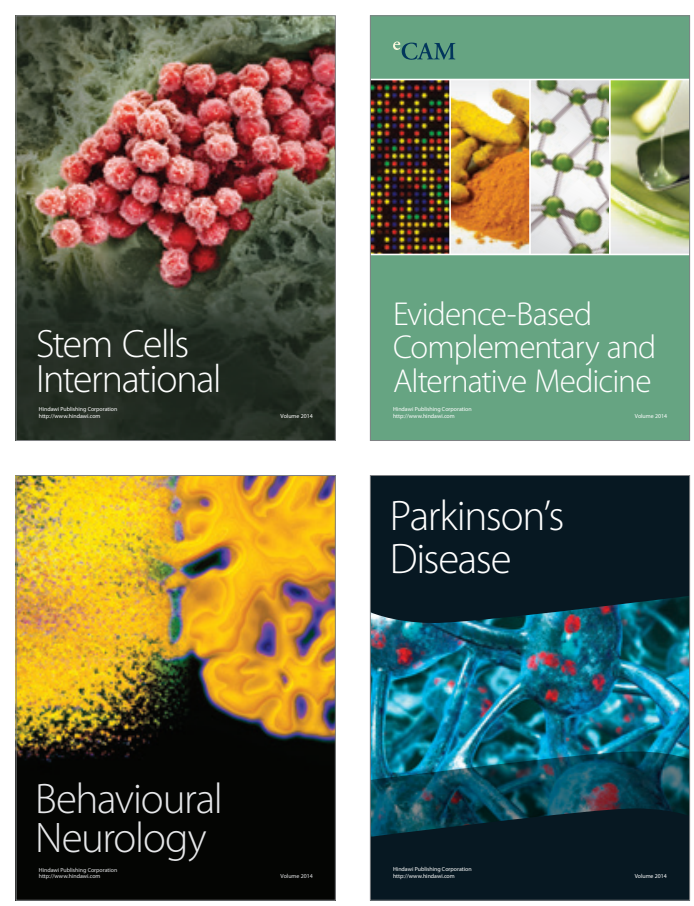

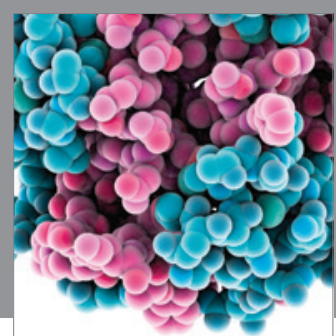

Journal of
Diabetes Research

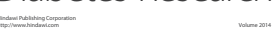

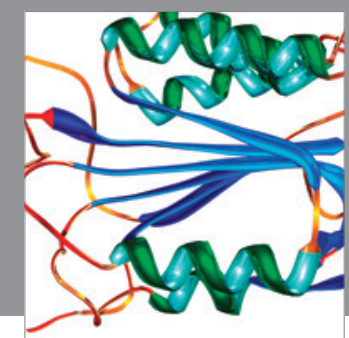

Disease Markers
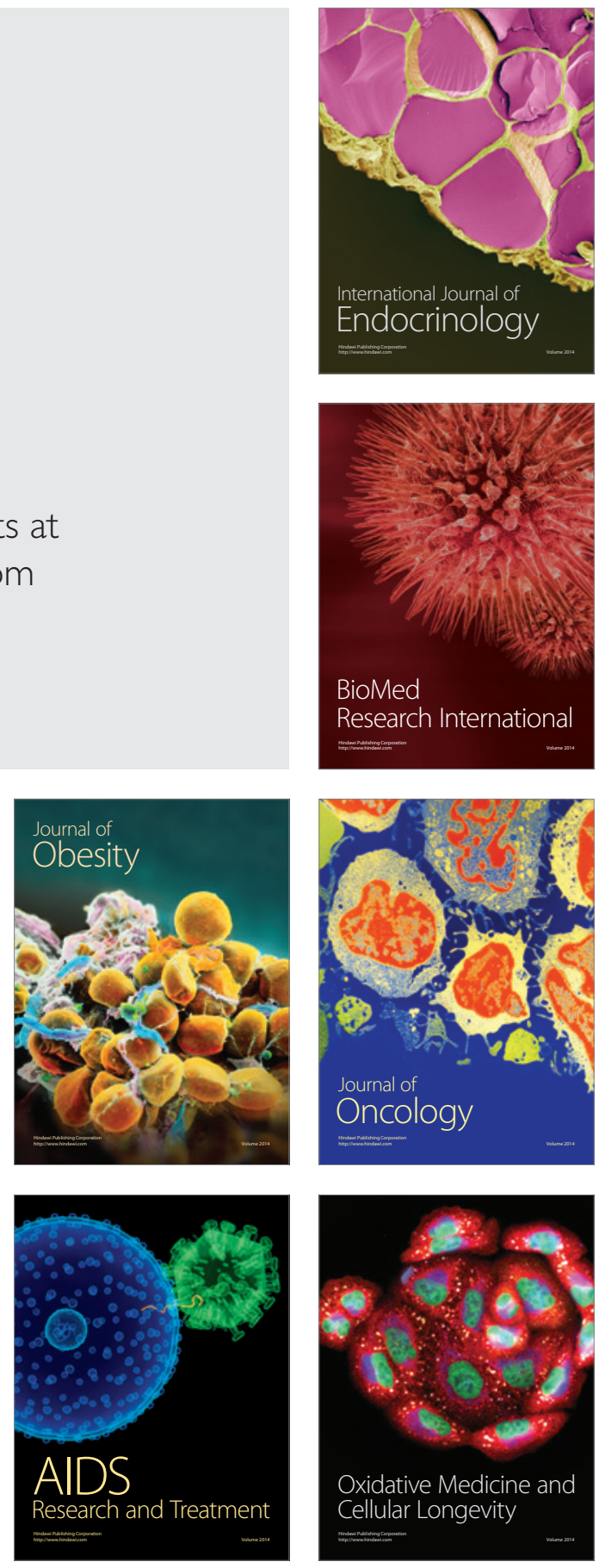